\title{
Development policies in Pampa del Indio: analysis of the implementation of the project Northern Argentina
}

\begin{abstract}
In this article, we're going to do an analysis on the project Northern Argentina (NA) Funded by development agencies and Implemento In the locality of Pampa del Indio, in the province of Chaco, located in the north of the Argentine Republic. For it at the beginning we will describe the process in which the indigenous communities were organized from the participation of religious groups in the area. Finally, we will explain that these indigenous organizations use the tools given by development agencies to generate opportunities where communities become known and visible. Our goal is to Explain that the Application Of policies moves away from the real local needs and produces exotic actors for commercial purposes from Tourist programs or sale of handicrafts, but that communities resignify these results for their benefit. This work responds to the research carried out between the years 2011 until the present, from the perspective of social anthropology, We rely on the ethnographic method and use Analytical techniques such as interviews and observations.
\end{abstract}

Volume 3 Issue 2 - 2018

Malena Castilla
Universidad de Buenos Aires, Argentina

Correspondence: Malena Castilla, Universidad de Buenos Aires, Argentina, Email malenacastilla@gmail.com

Received: December 27, 2017 | Published: April 26, 2018

Keywords: registries, development policies, organizations, indigenous

\section{Introduction}

Pampa del Indio is a locality located to the north of the province of Chaco in the Argentine Republic. According to the census carried out by the Intell of $2001^{1}$ lived in that place 11,558 inhabitants and in the data of the last census published by the same statistical agency in the year 2010 (INDEC), ${ }^{2}$ the population measured was 13,675 people of which 50 percent were recognized as rural pOblation. More than half of this percentage lives in places between 700 and 800 inhabitants, the rest of the population resides in places with less than 350 people in the forests of the region. During the years of the military dictatorship (1976-1983) in Argentina, non-governmental organizations (NGOs) were key in the construction and establishments of spaces of reflection and debate for those popular organizations that were opposed or not benefited from the policies and economics of the dictatorial regime of the time. For this reason, NGOs in this period became vehicles of resistance against the liberties that were being snatched from members of civil society.

In the Chaco region of northern Argentina, NGOs that had the greatest participation were those that were linked to religious spaces. In the year 1967 was created in the country the "movement of Priests for the Third World", within the Catholic Church Argentina. This council had a political and social stance based on defending the rights of the most unprotected sectors of society and was framed in the socalled TEología of the LIberación. The TEología of the LIberación was a current of thought of Christianity conformed by Catholics and Protestants in Latin America after the Second Vatican Council and the Medellín Conference in $1968 .^{3}$ In this scenario, marked by the influence of the theology of liberation, is created, in 1970, the Institute of Popular Culture (POCUIN) on the city of the Reconquista, in the province of Santa Fe, which intensifiesó Their work in the area during the democratic period (from the decade of 1980). POCUIN members sought to work with laypeople and members of the Catholic Church in communication-related projects, With the aim of carrying out activities with those populations that were affected by the acculturation product of large-scale urbanization. In the early years of the 1980, the Argentine pastoral selection has also been created (ARNAPATE) Led by a group of professionals and technicians and religious with interest collaborating with the most vulnerable populations in the region. It should be noted that during the decade of 1980 , non-governmental organizations increased their number and changed their focus in the previous decade.

In this sense, they began in this period to be established as channels in the implementation of development projects on behalf of Governments and international organizations. The NGO during the years of 1980 occupied the roles that Governments had. In the case of organizations such as Pocuin and Aanapate, they had a role as intermediaries, but in a context in which State policies did not change to the implementation of indigenous measures. In This Context Reemerged The expansionist policies of the state, Being the displacement of the natives of their territories the basis for the appropriation of the land and the conversion to the private property-the religious occupied a place of defense of these communities, of the abuses that suffered and of the unequal relation to which they were Submitted throughout the region.

These organizations Pocuin and Aanapate, they dedicated themselves to working with indigenous communities in the region from different activities, for example; to advise and organize legally the communities against judicial claims, technical and economic assistance of different productive projects, training in different Activities As well as the generation of educational teaching spaces, etc. From the end of the decade of 1980 until the Crisis of the year 2001, the neoliberal phase intensified in Chaco product of the arrival of multinationals of the agro-industry that obtained hectares for the cultivation of the negotiation with the provincial states. Thus, whereas in the year 1995 there were 4 million of hectares corresponding to the indigenous peoples of the zone and small producers the illegitimate sale 
of the lands led to that in 2007 only 660,000 remained ${ }^{4}$ In this sense, the social protest expressed in route cuts, manifestations and conflicts of varying magnitude, I have, on the one hand, the consolidation and reappearance of ethnic, Creole and peasant organizations in the Territories and, on the other hand, an increase of NGO interventions that founded their presence and action in a discourse that put the axis on the environment and works with the most vulnerable sectors of the population.

The last decade of the twentieth century is characterized by a deepening of the policies of neoliberal cutting, by the expansion on a global scale of a globalizing culture and by the crystallization of these horizons of the society in the public policies of the States National. In terms of income distribution, resources are used to benefit only the sector with the greatest purchasing power and not the population Majority which is ultimately the least capital. In this sense, the paternalistic and assimilation programs were the axis of the international cooperation agencies and sought to generate a change that promoted "multiculturalism". Although the NGOs were present throughout the Chaco region long before, they settled heavily in the town of Pampa del INdio during this period. It should be noted that this was an area in which the actions remained, for the most part, in the religious organizations that had settled in the previous decade.

A report by the Inter-American Development Bank (IDB) ${ }^{5}$ on indigenous peoples and sustainable development explains the reasons why the new organism was responsible for working with indigenous populations in Latin America. The correlation to explain poverty in Argentina was ethnic: in this case, the map of poverty in Argentina, according to the Insay in the census of 1991, revealed that areas with more basic needs not satisfied ${ }^{1}$ (NBI) coincided with the areas inhabited by indigenous communities. The indigenous communities of the Argentinean North became the center of the intervention of the organizations. Within these, the NGO of Religious orders (Pocuin, Arnapate, Fundapaz, etc.) worked with indigenous and peasant organizations. Among the organizations of Pampa del Indio we find that it currently complies, "Huo'o RA lyac NA alpi cha'aye retelataxan "Alpi" in Spanish means: beautiful women who care (from now on more Huo'o). Another organization was the Territorial Restitution Commission (CRT) ${ }^{2}$ Composed of different leaders of the community of Pampa del Indio. Both organizations were formed from the participation and advice of Pocuin. In the mid-1990, land claims of indigenous and Creole families Areed the intensification of soybean cultivation on a large scale and due to the end of the so-called "Cotton Spring". ${ }^{3}$ Later, in the year 1999, the "Indigenous Cacique

${ }^{1}$ According to the definition given by the Insay: "The concept of basic unmet needs (NBI) allows the delimitation of groups of structural poverty and represents an alternative to the identification of poverty considered only as insufficient income. This approach identifies the dimensions of absolute deprivation and focuses on poverty as a result of a cluster of essential material deprivations "(see: http://www.INDEC.gob.ar/nivel4_default.aspid tema_1=4\&id_tema_2=27\&id_tema_3=66 Last consultation date June 20 , 2017)

${ }^{2}$ Currently, the CRT is made up of 28 local communities.

${ }^{3}$ In the province of Chaco, cotton production entered a deep crisis in 1960 for oversupply and declining average yields. The maize and the grenadier sorghum were the crops that replaced cotton in this decade. Between 1976 and 1980 a new expansion of the white crop was recorded in the region. The so-called "white gold" suffered a sharp fall at the end of the decade of 1980 product of the retraction of the national textile industry. In 1991, with the external opening, the insertion of the economy into the commercial flow generated an international surge that was installed in the production of $\mathrm{Na}$. At the end of
Association" was created. This organization carried out a process of fighting for the land, which ended fourteen years later with the delivery of titles by the state. A detachment of this organization-at the same time-is the collective, Enauac Lapoota't which in Castilian means all together (hereinafter' Enauac) and which is presented as a social and political organization that works in pursuit of the defense and vindication of the Rights of the people Tobas. It was from the visibility of the indigenous communities, obtained by their work in different spaces and projects, that the ethnic organizations were consolidated not only territorially but also at the level Becoming key actors of international organizations. ${ }^{6,7}$ In this context, credit bureaus arrive in Pampa del Indio and organizations do not have governments with European income to implement development policies). ${ }^{8-10}$

\section{Case analysis of implementation of the development program in Pampa de Indio}

We will describe below the case analyzed from the implementation of the development program financed by the World Bank, in the locality of Pampa del Indio. This program was implemented through different government agencies, foundations and non-profit associations linked to agribusiness entrepreneurs. The project "Road infrastructure for the development of Northern Argentina" (hereinafter the project of development of the NA), which was implemented in the locality since the year 2011 through the intervention of the National Ministry of Federal Investments Planning, ${ }^{4}$ he contemplated works of water and roads. The national State through the Ministry of Planning, decided to make improvements in the construction of Provincial Route 3, which includes the Pampa section of the Indian-Villa Río Bermejito, with funds granted by the World Bank. The investment of 400 million dollars that were used for the accomplishment of this work, was executed after a social evaluation, in which the members of the Ministry of Planning relieved the zone to intervene and to the communities that would be affected. The World Bank, to deliver this type of loan establishes an appendix where it specifies that when a work is carried out that crosses an area inhabited by communities, it must work with them. Catalina, coordinator of the development project of the $\mathrm{Na}$, established in an interview that this addition made by the World Bank is seeking the protection of interests linked to capital transfers and agreements between government entities: the assistance of this unit derives from the Conditioning banks to make loans does not derive from the intent to protect the environment or indigenous peoples in the rural area, beyond what any company does to prevent tenants from ' disturbing'. This was more rigorous because the World Bank has very strong safeguards and is above social and indigenous Issues. ${ }^{11}$

Depending on this addition that requires working with the communities, the provincial government hired the foundation NOreste ARgentino, who has been working in the region since the decade of 1990. This foundation of Italian origin and financed by the Italian cooperation Nord Sud since the year 1988 and by the United Nations agency of the European Commission, proposed to work

the decade of the 1990 the cotton crisis reached the peak of the production of transgenics (soybean and cotton).

${ }^{4}$ The Ministry of Planning and Federal investment was one of the ministries of Argentina during several presidential efforts. Until the assumption of Mauricio Macri as president of the Nation, the ministry was in charge of the conduction of Julio de Vido, minister who remained in office during the governments of Nestor Kirchner (2003-2007) and Cristina Fernandez de Kirchner (2007-2011 and 2011-2015). 
with the ethnic communities through a project with the women's organizations of thes áAreas affected by the works. The World Bank, through the Ministry of Planning of the nation and in coordination with the foundation $\mathrm{Na}$, began working in the city of Pampa del Indio to, according to his speech, "safeguard the communities" and carry out, since then, the project called "Cultural Route Qom": The Culture Route Initiative Qom (CRQ) is to make A broker of seven cultural centers managed by women artisans Qom $-10 \%$ of the indigenous population of the country belongs to this ethnic group, distributed along the recently paved Route 3 in the province of Chaco, a work that was carried out as part of the plan of the indigenous peoples of the road infrastructure project for DES Creek de la Nort and Argentina (2011-2016) financed by the World Bank. ${ }^{12}$ The "Route of Culture Qom'It aims to market the artisanal production produced by the ethnic organizations of the area. This objective implied that from the production of these handicrafts, the indigenous communities would be inserted into the market, thus generating an economic independence. This would allow organizations Qom to enter a marketing circuit, not only of its products but also of its own culture from projects of "ethnic tourism'. The seven locations that cross the "cultural route" Qom"And in which the foundation NA He works with indigenous organizations: President Roca, Pampa Chica, fourth league, Pampa Grande, Fortin Lavalle, Villa Rio Bermejito, El Espinillo.

Of the survey, the technicians of the governmental and nongovernmental organizations found that in the localities there were already ethnic organizations and that there were other indigenous groups that were beginning to participate and build a collective reference in Around various social issues. In Pampa del Indio were linked to the organization Huo'o. As we have previously developed, this Organization has its antecedents in the year 1985 of the participation of Catholic organizations. Huo'o It was consolidated over time by other ethnic organizations, especially in the context of social protest. This organization, selected by the foundation $\mathrm{Na}$, not only worked for cultural recognition Qom but also in relation to the need to enforce the laws that established that intercultural education was a right as important as the restitution of the land. In this context, the indigenous organization Huo'o It was consolidated at the provincial level (where its members were recognized for their work as illustrious citizens by the Chamber of the right-handers of the province) and on the national stage (from the awards received in recognition of their educational projects and Vocational training). They have also been awarded internationally for their work in cultural recovery. In this sense, we could say that the development policies that sought to settle in Pampa del Indio with the objective of "consolidating indigenous organizations" already had an important level of concretion given the background that the organization had Huo'o in the locality. In addition, it should be clarified that one of the objectives of the project presented by the foundation is the construction of a community hall that already existed, since it had been created by this ethnic organization at the end of 1980 with the nuns of Arnapate And Pocuin.

According to the report made by the technicians of the World Bank, the objectives to be achieved with the project of the route of the culture Qom in the communities they were: construction of community centres; Workshops on artisanal techniques, insertion in productive processes, elaboration of papers on the right of women and refractive health and training on women's associations, among others. Beyond these objectives, ethnic organization was already working on the marketing of handicrafts, since historically it was Part of the financial support of their families and that is what allowed the daily work of the Organization, so this point was also resolved before the intervention of the foundation. Regarding the conduct of educational conferences on health, the indigenous organization in coordination with the University of the Northeast. He had been conducting training workshops on Law $n^{\circ} 26,485$ for comprehensive protection of women. In these talks. Members of Huo'o They not only met with the inhabitants of the community but also proposed translating the laws into the Toba language. ${ }^{13}$ In an interview we did to Flavia, President of the Foundation $\mathrm{Na}$, we explain the work they developed from the foundation from the project of the route of the culture Qom And how was the participation of this NGO in the work they are doing in the territory: since the foundation we have been working on development projects with the focus on women a while ago, with the empowerment of indigenous women and through DI Strategies generate income to achieve empowerment to dynamize these processes. Our goal is to empower women, that is, we believe that to work all the other issues there must be a strong issue that can demand public policies. Then they must go to the health table to the problems where these things arise. Health workshops or violence can be done, but no change will be generated. Empowerment is our focus of action, now we do not scatter Flavia, President of the Foundation Na, March 2016.

As we saw before, the ethnic organization Huo'o He has worked since the end of the decade of 1980 with the aim of achieving his cultural recognition, the preservation of his traditions and history. This organization also related to other indigenous and Creole movements in the area to have a bilingual and intercultural education in the locality, as established by the National Constitution. But the demands that it carries out are not only part of cultural but also territorial issues. Natural resources, as well as land, are a good that indigenous organizations argue historically with entrepreneurs who snatched them. In this sense, one of the activities developed by these ethnic organizations was the preparation of a map where the areas of Hunting, Collection and fishing, its sacred sites and cemeteries, among others. This work of toponymy was carried out by indigenous members, especially members of Huo'o, together with the collaboration of a Chilean anthropologist; Burgos, from the School of Anthropology of the Bolivarian University and to whom we were able to interview, explained to us how the process of preparing the map was: When I arrived in Pampa del Indio I was asked to make a territorial claim tool for Pocuin. It was not a concern of the organizations. It was a tool for the pros and I thought we had to do it with the communities and that was my first fight. We did an intercultural mapping workshop to generate territorial claim. It began with the construction as they see the territory, because they understand the geography and then they move to an educational field, to pass to the future generations a tool that can be read and directed by the children, as for the young people, as for the women and what $\mathrm{S}$ men (Interview Carlos Burgos, October 2016).

This map, which for the organization meant a hard work with all the indigenous communities in the area and that expresses how the territory was before the occupations of agro-livestock entrepreneurs, was used in the framework of the project "The route of Culture Qom". The maps on the provincial Route 3 point on the path inhabited by the indigenous communities, what they call these areas in the Toba language and where sacred places and ethnic cemeteries are found, as appears on the map they made with Burgos. However, neither the foundation NA Neither the Ministry of Planning placed these maps in the locality to recognize, recover and restore the territory that historically belongs to the communities, but with the aim of 
stimulating rural and ethnic tourism and turning the indigenous into a Tourist attraction. However, for communities to observe their own maps, collectively carried out in spaces of debate and reflection on historical and social memory, it means a historical vindication and the possibility of challenging these spaces. That is to say, this road project financed by an internationally renowned organism like the World Bank, generated the implantation of a tourist project and the exotización of the indigenous peoples, showing the "other ethnicity" without taking into account the demands, the rights and the struggles that organizations carry out.

This addition of the World Bank to work with the indigenous communities that are affected by road work, made it possible that from the intervention of the Foundation, the members of the organizationsin this case those of Huo'o- Make your fight visible internationally. In this sense, the members of the organization travelled to Italy and India as part of a program called "Slow Food". This international meeting, where members of 'exotic' communities from different parts of the world participated, with the aim of generating activities in pursuit of the development of nutritional strategies against junk food or ' fast food'. In this context, Huo'o's participation contributed by teaching the amount of natural and nutritious foods that can be made with a native seed like the carob tree. The members of the ethnic organization used this space full of representatives from different organizations, to resignify the activity relating their experiences not only as "native cooks" but also denouncing what happens in the region Soy Chaco expansion especially focused on the use of agrochemicals. Participants emphasized that these toxic products not only generate diseases in humans and animals, but also extinguish native vegetation.

It should be clarified that these agrochemicals are used mainly in soybean plantations in the region by different producers. Jorge Warsaw, nicknamed "The King of Soy", is one of the owners of large tracts of land in the agrobusiness and uses these products in their crops. Warsaw is part of a civil association called Civil Association for Integration and Development (acid) that works in coordination with the foundation NA In the project of the route of the Qom culture. The "King of soybeans" has more than 300,000 thousand hectares cultivated in Argentina and many others abroad and was the purchaser of the Agrofina plant that synthesizes and formulates a high value phytosanitary. Fitosanitairos are products used to combat The parasites and diseases that can have the crops, as well as exterminate the herbs and plants that surround them. When this agent is used in the environment, changes in the atmosphere, soil and water are generated. It is proven that its use contaminates and causes disorders in the health of living beings. In a newspaper in Valencia, Spain, they report how a group of experts denounced, from soil and water studies, their risks: the commission of the courts investigating the contamination of aquifers, a problem that particularly affects the regions of La Safor and the Ribera, continue to seek explanations. At the sessions held this week, experts noted the excess fertilizers and plant protection products used by farmers in the region as one of the main sources of this problem. The compresences made emphasis on the lack of control mechanisms for decades by the public administrations and criticized the lack of information on the consequences of this practice that reached the agricultural sector itself. "If something is clear is that excess fertilizer has contributed to the increase of nitrates dissolved in water, which generate various chemical reactions in the body and can degenerate into health problems," said one of the specialists (Levante;
Valencian Mercantile. 2016. "An excess in the use of phytosanitary contaminates water in La Safor and Ribera"). ${ }^{5}$

While the participation of Huo'o in such spaces, such as the meeting of Slow Food, served to denounce the conflicts that suffer in the locality, also was used to obtain greater economic benefits by the World Bank and the foundation $\mathrm{Na}$. We are interested to note that these international funding agencies do not recognize the processes of indigenous organization before their intervention in the territory, arguing that they were the same entities-Foundation NA and World Bank who organized communities in the Territories. In other words, there is no real accompaniment of these agencies to indigenous organizations, nor a solution to local problems (such as lack of access to water or territorial disputes). Catherine, member of the project of development of the NA, described in this regard that the local situation of the change of government in December of the year 2015 meant the paralysis of the planned works: they were going to make an aqueduct, it was a project that is going to equip many people and Stab starting the execution that was being done with the foundation $\mathrm{Na}$, but to stop and not to make the aqueduct that goes from rock to Pampas of India making community communities and then a lot of villages $T$ or the South.

A time after Cintia, foundation technique NA in charge of the area of Pampa del Indio, explained in an interview what was the situation that went through the planning of this work: an extension of the aqueduct was presented because it was not approved because extended budget and the provincial government now has to see where to MA funding... The aqueduct goes from Castelli to Miraflores and now lack of this side, but it was not approved, now we must see if the governor finds another Line of funding. In interviews with members of the ethnic organization-al-Asked about changes in their Cotidianeidades or about the benefits gained from participation in development policies-the answers they gave referred to the possibility of travelling and meeting other organizations with similar histories and with which they shared the same Claims. Also, for those members the intervention of the agencies meant the possibility of traveling abroad to make the situation known and to see their problems. However, despite these benefits, respondents never linked their participation in these programs with greater empowerment-which was one of the goals of the foundation NA in the project of the route of the culture Qom-Nor with improvements in relation to the infrastructure (vial or water) that benefit the community. As we analyse, the international financing projects that run in the territories with high degrees of territorial conflict and with difficulties of access to the resources like the water, do not consider these problems and thus, fail in the attempt. ${ }^{7}$ Another problem associated with agencies such as the Foundation NA It is the appropriation that they make of the work generated by the ethnic organizations, without recognizing their local history. An example of this is what happened to the case of the community Hall of Pampa Grande from the intervention of the company Samsung. The company, after donating some tablets and a desktop computer, determined that the community center would be called "Samsung ${ }^{5}$ Elevator; The Valencian Mercantile. "An excess in the use of phytosanitary contaminates water in La Safor and Ribera. Date of publication: December 4, 2016.

http://www.Levante-EMV.com/Safor/2016/12/04/exceso-fitosanitarioscontamina-agua-Safor/1500327.html 
Namum Village". This initiative eliminates the vision and worldview of the Organization Huo'o, who works in that room with the aim of preserving their culture in the face of western subjugation. Cintia, from the foundation $\mathrm{Na}$, is on this subject in an interview: Among the projects is Samsung because apart from what you want with the Nanum It's like a community eye. Nowhere does it say it's like an eye, but it's expected. Nanum It is a project with Samsung from the foundation that aims to generate a network of producers, "The future is on the mount" is called in the foundation. Business in network, to achieve the development of the native mountain and the revaluation of the traditional knowledge that the producers have The aim of these centres is to bring technological innovation closer to the isolated communities of the Gran Chaco. In this context, we observe how development policies in the Territory were implemented with the aim of increasing local production, but only to promote territorial and cultural subjugation. Likewise, these policies were implemented without analyzing the historical problems that the communities that live there, generating, ultimately, a greater inequality and exclusion of ethnic organizations from other local groups and the social gaze in general.

\section{Conclusion}

After years of dictatorship (1976-1983), social organizations of different types (indigenous, trade unions, small producers, among others) began to regain organizational capacity and work with objectives linked to the social rights of the Different groups. During this period and especially in the 1980, the indigenous communities began to organize themselves. Likewise, the NGOs They were inserted in this decade in the country through projects with funding of international origin such as the World Bank, the Inter-American Development Bank and among others. Despite these last two decades with economies Unstable and political conflicts, the society began to organize in groups that shared certain interests, either to solve family problems, neighbors or related to territorial claims, etc. It was from this social and political organization of these sectors, in particular of the indigenous communities of the north of the country, that the development agencies, foundations and associations linked to large national entrepreneurs began to work in the Implementation of policies aimed at this population. We have analyzed in this article, that the insertion of development agencies in the locality presented here, I mean, the implementation of policies that seek to generate commercial spaces through the indigenous presence. In this sense, many of the policies Exotizan to the native communities with which they are linked and generate economic market situations with their work of handicraft elaboration. However, the indigenous communities have been organized since the 1980 and their participation in these instances generated that they can use the tools that the development agencies provide. LAs indigenous communities in a process of updating and Adaptation They use the tools that these spaces provide them to be able to carry out their demands from a place of greater visibility.
And to say, beyond being part of projects that seek to exotizar the indigenous to market them as merchandise, these populations resist day by day from an active place, where the allegations and the fight are in force.

\section{Acknowledgements}

None.

\section{Conflict of interest}

Author declares that there is no conflict of interest.

\section{References}

1. National Institute of Statistics and Censuses. National census of Population, households and dwellings, Argentine Republic. 2001.

2. National Institute of Statistics and Censuses. National census of Population, households and dwellings, Argentine Republic. 2010.

3. Richard P. The ethical and spiritual strength of liberation theology: in the current context of globalization. Roads study. 2004.

4. Attías AM, Lombardo DR. Native population of the province of Chaco. Territories, domination and resistance. Buenos Aires, Theomai; 2014.

5. Deruyttere A. Indigenous peoples and sustainable development: the role of the Inter-American Development Bank. Inter-American Development Bank. 1997.

6. Trinchero HH, Leguizamón JM. Modernization borders. Reproduction of capital and workforce at the threshold of the Argentinean Chaco. National production and capital: Studies of economic Anthropology. 1995;15-44.

7. Biraben CN, Boivin M. Development of indigenous development projects in the indigenous communities of the Chaco of Salta, Argentina. Results. 2014;11(21):157-176.

8. Escobar A. The invention of the Third World: construction and deconstruction of development. Editorial Norma. 1998.

9. Esteva G. Culture and development: the viewpoint of anthropology. In: Viola A, editor. Development anthropology. Buenos Aires: Paidos; 2000.

10. Isla A, Colmegna P. Introduction: Politics and culture in developmen interventions. Politics and power in the development process. Science editorial: FLACSO; 2005.

11. Elevator. The Valencian Mercantile: An excess in the use of pesticides contaminates water in La Safor and Ribera. 2016

12. World Bank Group. Ways to increase women's capacity for action and decision-making, Initiative of the route of the Qom culture, province of Chaco-Argentina, Road infrastructure project for the development of the Norte Grande (2011-2016). 2016.

13. Reboratti C. Society, environment and regional development in the upper basin of the Bermejo River. Buenos Aires: Institute of Geography, University of Buenos Aires; 1996. 